\title{
DECOMPOSITION OF DIVERSE LITTER MIXTURES IN STREAMS
}

\author{
Antoine Lecerf,,${ }^{1,4}$ Geta Risnoveanu, ${ }^{2}$ Cristina Popescu, ${ }^{2}$ Mark O. Gessner,${ }^{3}$ and Eric Chauvet ${ }^{1}$ \\ ${ }^{1}$ Laboratoire Dynamique de la Biodiversité, UMR 5172 CNRS UPS, 29 rue Jeanne Marvig, 31055 Toulouse, France \\ ${ }^{2}$ Department of Systems Ecology and Sustainable Development, University of Bucharest \\ Splaiul Indepedentei 91 95, 050095 Bucharest, Romania \\ ${ }^{3}$ Department of Aquatic Ecology, Eawag: Swiss Federal Institute of Aquatic Science and Technology, \\ and Institute of Integrative Biology (IBZ), ETH Zurich, 6047 Kastanienbaum, Switzerland
}

\begin{abstract}
In view of growing interest in understanding how biodiversity affects ecosystem functioning, we investigated effects of riparian plant diversity on litter decomposition in forest streams. Leaf litter from 10 deciduous tree species was collected during natural leaf fall at two locations (Massif Central in France and Carpathians in Romania) and exposed in the field in litter bags. There were 35 species combinations, with species richness ranging 110 . Nonadditive effects on the decomposition of mixed species litter were minor, although a small synergistic effect was observed in the Massif Central stream where observed litter mass remaining was significantly lower overall than expected from data on single species litter. In addition, variability in litter mass remaining decreased with litter diversity at both locations. Mean nitrogen concentration of single and mixed species litters $(0.68 \quad 4.47 \%$ of litter ash free dry mass) accounted for a large part of the variation in litter mass loss across species combinations. For a given species or mixture, litter mass loss was also consistently faster in the Massif Central than in the Carpathians, and the similarity in general stream characteristics, other than temperature, suggests that this effect was largely due to differences in thermal regimes. These results support the notion that decomposition of litter mixtures is primarily driven by litter quality and environmental factors, rather than by species richness per se. However, the observed consistent decrease in variability of decomposition rate with increasing plant species richness indicates that conservation of riparian tree diversity is important even when decomposition rates are not greatly influenced by litter mixing.
\end{abstract}

Key words: biodiversity; context dependency; ecosystem functioning; leaf breakdown; litter nitrogen; litter quality; nonadditive effects; riparian vegetation; stability.

\section{INTRODUCTION}

There has been growing interest over the past decade in assessing the significance of biodiversity for ecosystem functioning. Most studies have examined the importance of plant diversity for primary productivity and its stability in grasslands (e.g., Hector et al. 1999, Tilman et al. 2001, 2006, van Ruijven and Berendse 2005), and these experiments have usually provided clear evidence for positive effects of species richness (see Hooper et al. [2005] for a comprehensive review). Consequences of changing biodiversity on other ecosystem processes have also been addressed (Jonsson and Malmqvist 2000, Covich et al. 2004, Hättenschwiler et al. 2005, Spehn et al. 2005, Wojdak 2005). Particular attention has been given to plant litter decomposition (e.g., Wardle et al. 1997, Swan and Palmer 2004, Hättenschwiler and Gasser 2005, Lecerf et al. 2005, Moore and Fairweather 2006) to determine whether this critical complementary process in terrestrial and many aquatic ecosystems

Manuscript received 21 February 2006; revised 3 July 2006; accepted 7 July 2006. Corresponding Editor: C. Hupp.

${ }^{4}$ Present address: Department of Forest Sciences, Univer sity of British Columbia, Vancouver, British Columbia V6T 1Z4 Canada. E mail: Antoine.Lecerf@ubc.ca
(Webster and Benfield 1986, Wagener et al. 1998, Moore et al. 2004) also is affected by plant species diversity.

According to current concepts, litter decay rates are driven by both extrinsic and intrinsic factors. These include moisture, temperature, external nutrient supply, and litter quality (Webster and Benfield 1986, Coûteaux et al. 1995, Gessner et al. 1997, Berg and McClaugherty 2003). Within a given system, concentrations of nutri ents ( $\mathrm{N}$ and $\mathrm{P}$ ) and refractory leaf constituents are generally useful litter traits to predict decomposition rates of single species litter (Melillo et al. 1982, Gessner and Chauvet 1994, Heal et al. 1997, Hobbie 2005). However, whether and to what extent mixing litter alters the control of litter quality on decomposition is poorly documented.

Litter diversity effects on litter decomposition can be tested by mixing various litter species and comparing decay rates of the mixtures with rates predicted from the component species decomposing in isolation (Wardle et al. 1997, Gartner and Cardon 2004, Hättenschwiler et al. 2005). Diversity effects are indicated when litter mixtures do not decay at rates predicted from the component species. Mechanisms that could be respon sible for the effects of litter mixtures on decomposition include the possible transfer of nutrients (e.g., N, P, Ca) 

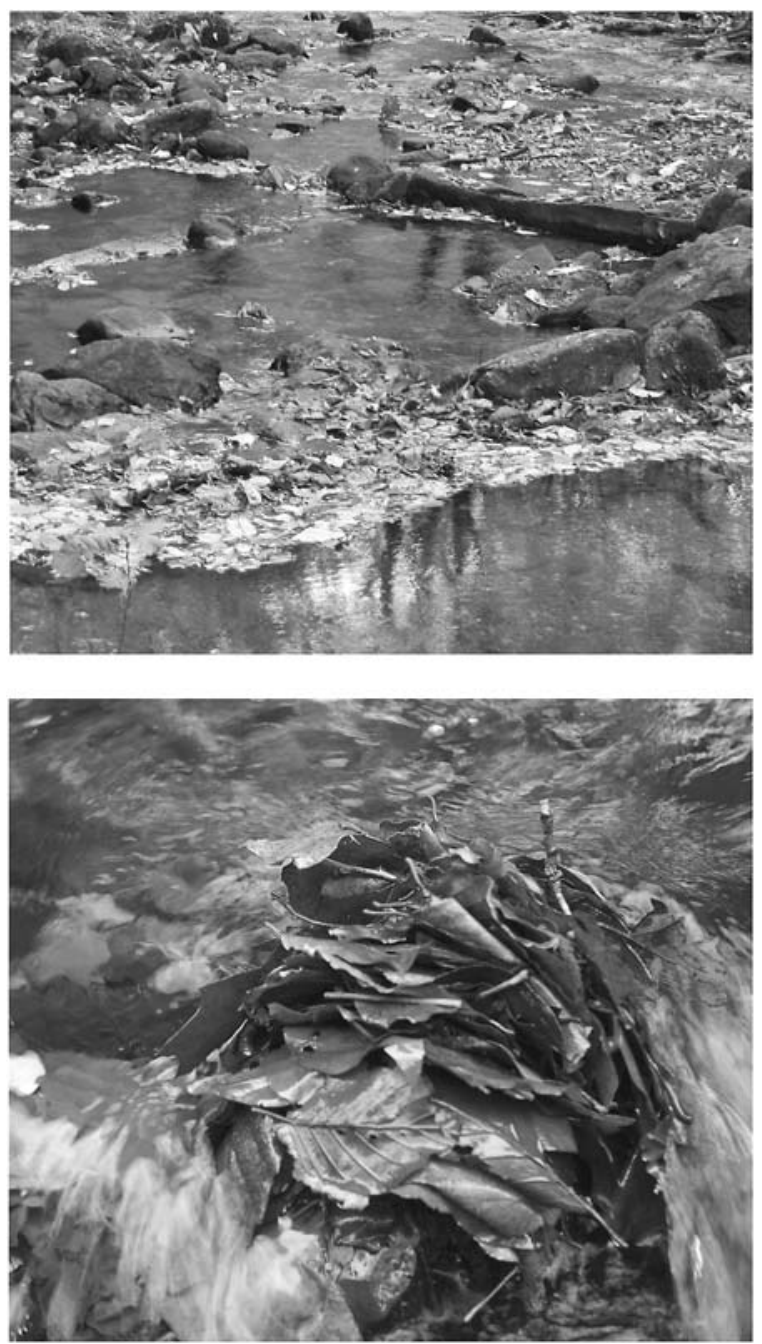

Plate 1. Leaf litter in a stream flowing through temperate deciduous forest. In autumn, such streams are supplied by tremendous amounts of leaf litter (top photo) which accumulate in front of obstacles to form diverse leaf patches (bottom photo). Photo credits: E. Chauvet and A. Lecerf.

or certain essential organic compounds (e.g., vitamins and some fatty acids) from litter species rich in these elements or molecules to litters with low concentrations. The outcome of such transfers should be an acceleration of decomposition in species mixtures, because nutrients and/or other essential compounds are used more efficiently overall (Hättenschwiler et al. 2005). Con versely, inhibitory cell constituents released from some leaves in species mixtures, especially water soluble compounds such as phenolic substances, could slow decomposition even of species that do not contain these compounds themselves (Hättenschwiler et al. 2005). In addition, litter diversity could be mediated through alteration of the microenvironment where decomposi tion occurs (Gartner and Cardon 2004, Hättenschwiler et al. 2005) or behavioral responses of invertebrates feeding on litter (Hättenschwiler and Gasser 2005, Zimmer et al. 2005, Swan and Palmer 2006b).

In a literature synthesis on biodiversity and litter decomposition, litter diversity effects have been ob served in the majority of experiments (Gartner and Cardon 2004). However, these significant effects have varied across studies in terms of both direction and magnitude, and lack of effects has also been noted (Gartner and Cardon 2004, Hättenschwiler et al. 2005). In addition to differences in litter quality and methods, discrepancies across studies may be due to differences in environmental conditions (e.g., Cardinale et al. 2000, Spehn et al. 2005, Wojdak 2005). Evidence for this idea of context dependency comes from studies where the presence or composition of litter associated inverte brates was altered concomitantly with litter diversity (Hättenschwiler and Gasser 2005, Schädler and Brandl 2005, Zimmer et al. 2005, Swan and Palmer 2006a). Decomposition experiments with litter mixtures would therefore be strengthened if they were replicated at different sites with species composition of treatments kept constant.

Most experiments addressing litter diversity decom position relationships have been conducted in grasslands or forests (Gartner and Cardon 2004, Hättenschwiler et al. 2005), whereas information on forest streams and other aquatic environments is limited (Swan and Palmer 2004, LeRoy and Marks 2006, Moore and Fairweather 2006). Forest streams are characterized by (1) large amounts of leaf litter that constitutes the main energy supply to food webs (Richardson 1992, Wallace et al. 1999); (2) multispecies litter accumulations in front of obstacles (see Plate 1), which represent ephemeral resource patches and can easily be simulated and manipulated in experiments (Petersen and Cummins 1974, Finn 2001); (3) absence of moisture effects, which often govern decomposition dynamics in terrestrial environments (Berg and McClaugherty 2003, Kuehn et al. 2004); and (4) substantially faster decomposition than on land (Webster and Benfield 1986, Wagener et al.

TABLE 1. Stream characteristics at the study sites during experiments in the Massif Central and Carpathians.

\begin{tabular}{lcc}
\hline \hline & \multicolumn{2}{c}{ Location } \\
\hline \multicolumn{1}{c}{ Parameter } & Massif Central & Carpathians \\
\hline Starting date of experiment & 11 Dec 2003 & 21 Nov 2003 \\
Final sampling date & 14 Jan 2004 & 10 Feb 2004 \\
Duration of experiment $(\mathrm{d})$ & 34 & 81 \\
Degree days & 272 & 122 \\
Water temperature $\left({ }^{\circ} \mathrm{C}\right) \dagger$ & $8.0 \pm 0.2$ & $1.5 \pm 0.2$ \\
$\mathrm{pH}$ & $6.9 \pm 0.1$ & $7.9 \pm 0.2$ \\
$\mathrm{Conductivity}(\mu \mathrm{S} / \mathrm{cm})$ & $34 \pm 2$ & $221 \pm 20.4$ \\
$\mathrm{NO}_{3}(\mu \mathrm{g} \mathrm{N} / \mathrm{L})$ & $976 \pm 139$ & $866 \pm 131$ \\
$\mathrm{PO}_{4}{ }^{3}(\mu \mathrm{g} \mathrm{P} / \mathrm{L})$ & $2.8 \pm 0.2$ & $3.8 \pm 2.3$ \\
$\mathrm{NH}_{4}{ }^{+}(\mu \mathrm{g} \mathrm{N} / \mathrm{L})$ & $1.5 \pm 1.4$ & $17.4 \pm 5.8$ \\
\hline
\end{tabular}

Note: Means $( \pm \mathrm{SE})$ are given for water chemistry data $(n \quad 3$ sampling dates).

$\dagger$ Mean $( \pm$ SE) water temperature was calculated from mean daily temperature. 
TABLE 2. Mass remaining in single species litter bags and initial nitrogen concentrations of 10 litter species (mean \pm SE) decomposing in two similar streams at geographically distant locations.

\begin{tabular}{|c|c|c|c|c|c|}
\hline \multicolumn{2}{|c|}{ Species } & \multicolumn{2}{|c|}{ Mass remaining (\%) } & \multicolumn{2}{|c|}{$\mathrm{N}(\%$ AFDM $)$} \\
\hline Latin name & Common name & Massif Central & Carpathians & Massif Central & Carpathians \\
\hline Fagus silvatica & Beech & $83.7 \pm 1.4$ & $88.5 \pm 0.9$ & $1.23 \pm 0.02$ & $0.90 \pm 0.02$ \\
\hline Quercus rubra & Red Oak & $75.0 \pm 2.8$ & $85.2 \pm 1.3$ & $0.68 \pm 0.02$ & $0.81 \pm 0.04$ \\
\hline Quercus robur & Oak & $58.4 \pm 7.4$ & $78.1 \pm 1.3$ & $1.14 \pm 0.02$ & $0.86 \pm 0.01$ \\
\hline Betula pendula & Birch & $62.2 \pm 4.4$ & $59.7 \pm 2.0$ & $1.03 \pm 0.01$ & $1.15 \pm 0.03$ \\
\hline Ulmus minor & Elm & $25.8 \pm 3.8$ & $28.4 \pm 5.9$ & $0.94 \pm 0.01$ & $1.79 \pm 0.02$ \\
\hline Acer pseudoplatanus & Maple & $18.4 \pm 2.4$ & $58.2 \pm 6.1$ & $1.11 \pm 0.09$ & $1.01 \pm 0.02$ \\
\hline Corylus avellana & Hazel & $19.6 \pm 7.5$ & $75.0 \pm 6.0$ & $1.36 \pm 0.03$ & $1.19 \pm 0.01$ \\
\hline Alnus glutinosa & Alder & $19.7 \pm 6.5$ & $33.7 \pm 4.2$ & $2.83 \pm 0.07$ & $3.46 \pm 0.07$ \\
\hline Fraxinus excelsior & Ash & $4.8 \pm 2.2$ & $37.2 \pm 4.1$ & $2.75 \pm 0.06$ & $2.70 \pm 0.17$ \\
\hline Sambucus nigra & Elderberry & $1.2 \pm 0.1$ & $0.0 \pm 0.0 \dagger$ & $3.01 \pm 0.03$ & $4.47 \pm 0.08$ \\
\hline
\end{tabular}

$\dagger$ No litter remaining in any of the litter bags

1998). Together, these features should make forest streams a useful model system to address questions about litter diversity decomposition relationships.

The present study aimed to test the extent to which litter diversity alters decomposition in streams. The experiment involved a large number of litter species (10) and many combinations (25) of litter mixtures to assess the importance of litter species richness for both decomposition rates and the variability of these rates. To assess the possible influence of geographical context, identical experiments were conducted in two streams with similar characteristics, but situated at great distance from one another. Finally, determination of initial litter nitrogen concentrations was intended to shed light on the importance of litter quality for the decomposition of litter species mixtures.

\section{Methods \\ Experimental sites}

A litter mixture experiment was conducted in the autumn and winter of 20032004 in two forest streams in the Massif Central, France $\left(43^{\circ} 25^{\prime} 29.5^{\prime \prime} \mathrm{N}, 2^{\circ} 13^{\prime} 29.3^{\prime \prime}\right.$ E, elevation $720 \mathrm{~m}$ ) and the Carpathians, Romania $\left(45^{\circ} 23^{\prime} 46.5^{\prime \prime} \mathrm{N}, 25^{\circ} 33^{\prime} 22.2^{\prime \prime}\right.$ E, elevation $\left.1053 \mathrm{~m}\right)$. Both sites were second order reaches in beech (Fagus silvatica L.) forests and had similar channel morphology and streamside vegetation. This included common riparian tree species, such as ash (Fraxinus excelsior L.), alder (Alnus glutinosa (L.) Gaertn.), maple (Acer pseudoplata nus L.), and hazelnut (Corylus avellana L.). Stream water temperature was continuously monitored with calibrat ed temperature data loggers (SmartButton, ACR Systems, Surrey, British Columbia, Canada). Through out the experiments, temperature was much higher in the Massif Central than in the Carpathians, whereas differences in water chemistry were small, especially in terms of nutrient concentrations (Table 1).

\section{Litter bag experiment}

Leaves from 10 woody plant species, present at both locations, were collected just after abscission and air dried for at least two weeks at room temperature $\left(\sim 20^{\circ} \mathrm{C}\right)$. The selected litter species encompassed a broad range of decomposability (Table 2). Leaflets of ash and elderberry, and whole leaves of all other species, were used. Stalks were removed from maple leaves.

Litter bags consisted of $4.0 \pm 0.2 \mathrm{~g}$ (mean air dry mass \pm range) of leaf litter enclosed in bags $(13 \times 19 \mathrm{~cm})$ made of $10 \mathrm{~mm}$ mesh screen to allow access to the largest detritivorous invertebrates, which were case bearing caddisfly larvae (Lecerf et al. 2005; G. Risno veanu, unpublished data). Before placing weighed leaves in bags, they were wetted with distilled water from a vaporizer to prevent breakage during handling and transport. Species mixtures were assembled with the total mass partitioned equally among species, recording the exact mass of litter used. Because testing all combinations of species mixtures was impracticable, six species combinations were drawn at random for each of four intermediate richness levels: 2, 4, 6, and 8 species. Thus the experiment encompassed 35 treatments, including 10 single species litters decomposing in isola tion, one 10 species mixture, and a total of 24 random species mixtures comprising 28 species. There were four replicate bags of each litter treatment per location, each submerged in a separate riffle that served as blocking factor. Litter bags were randomly distributed within each riffle, in groups of seven on $3 \mathrm{~m}$ lines, $\sim 0.4$ $\mathrm{m}$ apart. The five lines per riffle were set up parallel to the flow and were also $0.4 \mathrm{~m}$ apart. Lines were secured with three $10 \mathrm{~mm}$ diameter rebars, and stones were placed on top of them to maintain bags on the stream bottom and ensure natural invertebrate colonization.

The litter bags were retrieved from streams after 34 and 81 days in the Massif Central and Carpathians, corresponding to 272 and 121 degree days, respectively. These sampling dates corresponded to the time when $\sim 50 \%$ of the initial litter mass was lost from the 10 species mixture, as estimated by removing extra litter bags during the experiment. Litter samples were cleaned with tap water, dried at $105^{\circ} \mathrm{C}$ for $48 \mathrm{~h}$, and weighed to the nearest $0.01 \mathrm{~g}$. Ash free dry mass (AFDM) was determined after combustion of subsamples at $550^{\circ} \mathrm{C}$ for $4 \mathrm{~h}$. Four unexposed samples of each litter species were 

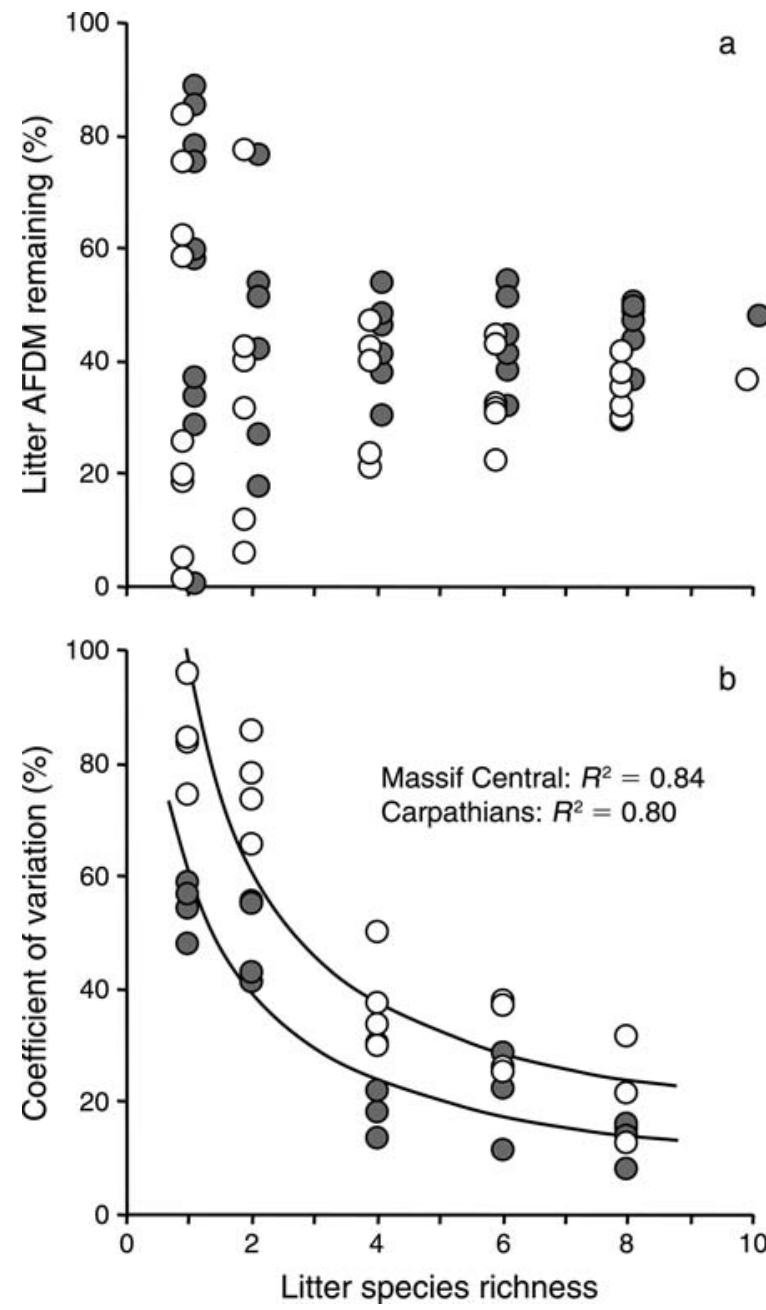

FIG. 1. Effects of litter species richness on (a) decomposi tion determined as litter ash free dry mass (AFDM) remaining, and (b) the coefficient of variation (CV) of litter mass remaining in a Massif Central stream (open circles) and a Carpathian stream (shaded circles). Coefficients of variation among species combinations were calculated separately for each riffle and fitted to power functions.

used to determine the initial dry mass and AFDM in the same way.

The initial nitrogen $(\mathrm{N})$ content of the 10 litter species was determined on ground subsamples with CHN analyzers (NA 2100, CE Instruments, ThermoQuest, Milan, Italy; CHNOS VARIO EL III, Elemental Analysensysteme GmbH, Hanau, Germany). Mean N concentration of the litter mixtures comprising $n$ species was calculated as follows:

$$
N=\frac{\sum_{i}^{n}\left(N_{i} \times \mathrm{AFDM}_{i}\right)}{\sum_{i=1}^{n} \operatorname{AFDM}_{i}}
$$

where $N_{i}$ is the $\mathrm{N}$ concentration (by percentage AFDM) and $\mathrm{AFDM}_{i}$ is the initial AFDM of litter species $i$.
Decomposition was determined as percentage litter AFDM remaining over the duration of experiments. Expected mass remaining $(E)$ in litter mixtures was calculated as follows:

$$
E=\frac{\sum_{i=1}^{n}\left(\operatorname{AFDM}_{i} \times O_{i}\right)}{\sum_{i}^{n} \mathrm{AFDM}_{i}}
$$

where $\mathrm{AFDM}_{i}$ is the initial AFDM of litter species $i$, and $O_{i}$ the observed percentage of litter AFDM remaining of species $i$ in the single species litter bag from the same riffle.

Deviation between the observed and expected mass remaining in litter mixtures was calculated as difference $O E$. Values not different from zero indicate additivity, whereas positive and negative values suggest antagonis tic and synergistic effects on decomposition, respective ly. Instead of calculating relative deviations (i.e., $(O$ $E) / E$; Wardle et al. 1997, Loreau 1998), $E$ was used as covariate in statistical analyses, which provides a formal test for the influence of $E$ on $O \quad E$.

\section{Statistical analyses}

Paired $t$ tests were used to assess whether observed and expected mass remaining in individual mixed species litter bags differed in each of the two study streams. Hierarchical ANOVA and ANCOVA were used to test whether observed litter mass remaining and the difference $O \quad E$ depended on location, riffle as blocking factor nested in location, litter species richness, the interaction location $\times$ richness, species composition nested in richness, and the interaction location $\times$ composition nested in location $\times$ richness. This model required calculation of multiple error terms (Schmid et al. 2002): location vs. riffle, richness vs. composition, location $\times$ richness vs. location $\times$ composition, and all other terms vs. the residual error. Since the graphical display of data did not suggest a particular shape of the diversity functioning relationship, litter species richness was treated in this analysis as categorical factor, rather than as continuous variable in a regression analysis. Using Type I sums of squares, expected litter mass remaining $(E)$ as covariate was introduced last in the ANCOVA on the difference $O \quad E$ in order not to interfere with correlated factors, such as species com position of litter mixtures (see Hector et al. 2000, Tilman et al. 2001). Litter mass remaining data were square root transformed before analyses to alleviate heteroscedas ticity and improve normality.

Effect of litter diversity on the variability of decom position was assessed by nonlinear regression analysis according to $\mathrm{CV}=a S^{b}$, where $\mathrm{CV}$ is the coefficient of variation of litter AFDM remaining, $S$ is litter species richness, and $a$ and $b$ are constants (Doak et al. 1998, Tilman et al. 1998, Dang et al. 2005). Values of CV at each richness level were calculated separately for each 
TABLE 3. Summary of ANOVA of observed litter mass remaining in single and mixed species litter bags in two streams of the Massif Central and the Carpathians (location). Data were square root transformed before analysis.

\begin{tabular}{lrrrrrc}
\hline \hline \multicolumn{1}{c}{ Source of variation } & df & \multicolumn{1}{c}{ SS } & SS (\%) & MS & \multicolumn{1}{c}{$F$} & $P$ \\
\hline Location & 1 & 80.6 & 8.5 & 80.6 & 29.3 & 0.002 \\
Riffle(location) & 6 & 16.5 & 1.7 & 2.7 & 7.8 & $<0.0001$ \\
Species richness & 5 & 3.2 & 0.3 & 0.6 & 0.0 & 1.00 \\
Species composition(richness) & 29 & 692.9 & 73.4 & 23.9 & 68.3 & $<0.0001$ \\
Location $\times$ richness & 5 & 4.8 & 0.5 & 1.0 & 0.4 & 0.86 \\
Location $\times$ composition(richness) & 29 & 74.8 & 7.9 & 2.6 & 7.4 & $<0.0001$ \\
Error & 204 & 71.4 & 7.6 & 0.4 & & \\
Total & 279 & 944.2 & 100.0 & & & \\
\hline
\end{tabular}

stream riffle. The effect of initial litter $\mathrm{N}$ concentration on decomposition was assessed by nonlinear regression analysis according to $O=a e^{b N}$, where $O$ is the observed percentage litter AFDM remaining, $N$ is the initial nitrogen concentration of litter, and $a$ and $b$ are constants. Regression analyses were carried out sepa rately at both locations using nonlinear curve fitting, and differences in regression model coefficients were assessed by ANCOVA on log log transformed data (effects of diversity on variability) or log transformed data (litter $\mathrm{N}$ effects).

Statistica 6.0 (StatSoft 2001) was used for all statistical analyses. The ANOVA, ANCOVA and nonlinear regression analyses were performed using the GLM procedure.

\section{Results}

The observed litter mass remaining varied among species combinations over a similar range at both locations (1.2 $83.7 \%$ in the Massif Central and 0.0 $88.5 \%$ in the Carpathians; Fig. 1a, Table 2). Litter species composition overwhelmed all other sources of variation in litter mass remaining (sum of squares in Table $3=73.4 \%$ ). Location, riffle, and the location $\times$ composition interaction also had significant effects on litter mass remaining (Table 3), whereas no significant effect of species richness was found (richness, $P=1.00$; location $\times$ richness, $P=0.86$; Fig. 1a).

Mean mass remaining of litter mixtures observed in the Massif Central was slightly lower (by 2.8\%) than expected (Fig. 2a; paired $t$ test of observed vs. expected values, $\left.t_{99}=3.81, P<0.001\right)$. This indicates that mixing litter had a small positive (i.e., synergistic) effect on litter decomposition. In the Carpathians, in contrast, the mean observed and expected mass remaining were virtually the same (Fig. 2a; paired $t$ test, $t_{99}=0.083, P$ $=0.93$ ), reflecting an overall lack of either antagonistic or synergistic effects of litter mixing on decomposition rate.

Respectively, $8 \%$ and $19 \%$ of individual litter mixtures in the Massif Central and Carpathians decomposed at rates very close to those expected from single species litter bags (i.e., observed and expected litter mass remaining differed by $<1 \%$ ). The other litter mixtures decomposed either faster $(59 \%$ and $43 \%$ of the points were below the 1:1 lines in Fig. 2b, c, respectively) or more slowly (33\% and $38 \%$ of the points were above the 1:1 lines in Fig. 2b, c, respectively) than expected. The difference $O \quad E$ was strongly related to the expected litter mass remaining $(E)$ used as covariate in the ANCOVA (Table 4). It also differed between the Massif Central and the Carpathians for a given species combination, as reflected in a significant interaction between location and species composition $(P=0.034$; Table 4). The mean difference between observed and expected mass remaining of a given species mixture ranged from $0.2 \%$ to $9.5 \%$ in the Massif Central, and the corresponding range in the Carpathians was $0.1 \%$ to $6.2 \%$ (data not shown).

Mixing litter consistently reduced variability in litter mass remaining across species combinations as richness increased from one to eight leaf species (Fig. 1b). This relationship was well described by a power function for both locations $\left(R^{2} \geq 0.80, P<0.001\right)$. However, mean $\mathrm{CV}$ values were higher in the Massif Central than in the Carpathians (ANCOVA after log log transformation of data; intercept, $F_{1,36}=7.3, P=0.010$; slope, $F_{1,36}=0.02$, $P=0.90$; Fig. 1b).

Large variation among species was found for initial $\mathrm{N}$ concentrations of litter. Concentrations ranged from $0.68 \%$ to $3.01 \%$ of AFDM in the Massif Central and from $0.81 \%$ to $4.47 \%$ in the Carpathians (Table 2). Mass remaining of single species litter was related to the initial litter $\mathrm{N}$ concentration in both streams by a negative exponential function $\left(R^{2}>0.48, P<0.01\right.$; Fig. 3a, b, dashed lines), and results were similar when all species combinations including mixtures were used in the analyses ( $R^{2}>0.47, P<0.001$; Fig. 3a, b, solid lines). An ANCOVA conducted on the log transformed data for litter mass remaining indicated that model coeffi cients did not significantly differ between locations (intercept, $F_{1,66}<0.1, P=0.81$; slope, $F_{1,66}=1.8, P=$ $0.18)$.

\section{Discussion}

An interesting finding of the present study is that litter species richness had at most small effects on decompo sition rate when comparing litter mixtures across a wide range of species showing large differences in decompos ability. The mean difference between observed and 

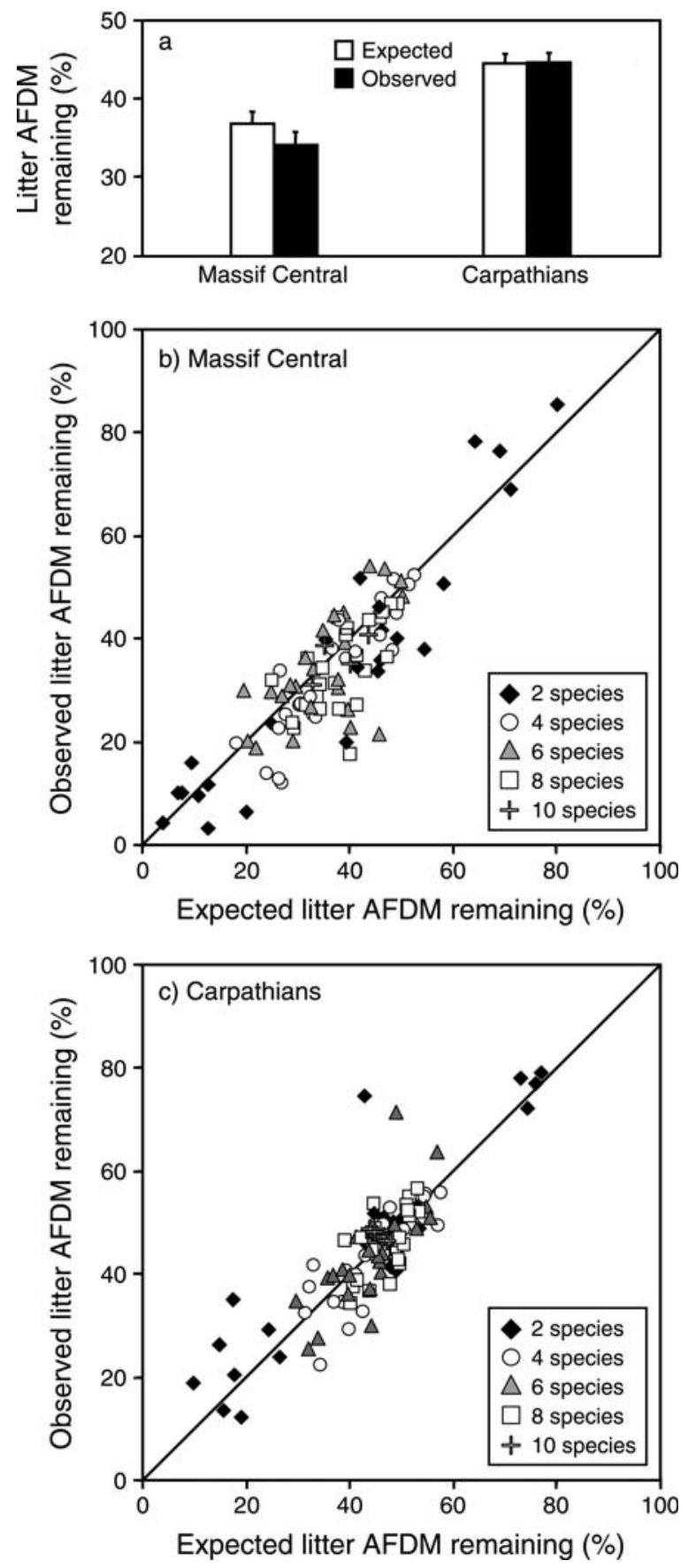

FIG. 2. Observed and expected litter mass remaining in mixed species litter bags exposed in streams. (a) Bars represent grand means ( $+\mathrm{SE}$ ) of expected (open bars) and observed (filled bars) litter mass remaining. Scatter plots show observed vs. expected mass remaining for individual litter bags in the (b) Massif Central, and (c) Carpathians. Deviation from the 1:1 line indicates litter diversity effects on decomposition of litter mixtures.

expected litter mass remaining of a given species mixture never exceeded $10 \%$ of initial litter mass, and sign and magnitude of the differences (positive or negative) varied among individual mixed litter bags (Fig. 2).
These relatively small and inconsistent effects of litter diversity support the idea that litter decomposition is less responsive to variation in plant species richness than is primary productivity (Wardle et al. 1997, Hector et al. 2000). In addition, our results are consistent with the outcome of a literature synthesis that assessed litter diversity effects on decomposition (Gartner and Cardon 2004) and found higher occurrence of positive (i.e., synergistic) than negative (i.e., antagonistic) effects overall (47.5\% vs. $19 \%$ of the reviewed cases).

Although not strong, a significant positive diversity effect across all litter mixtures in the present study was observed in the Massif Central, but not the Carpathians (Fig. 2a). This discrepancy between locations, despite the use of identical leaf species and experimental designs, supports the idea that litter diversity effects on decomposition are context dependent. Evidence from a model and experiments in other systems also indicates that environmental factors can alter biodiversity eco system functioning relationships (Cardinale et al. 2000, Spehn et al. 2005, Wojdak 2005). For example, in a stream study, litter diversity effects on decomposition observed in summer disappeared when repeating the experiment in fall (Swan and Palmer 2004). It is worth noting that the direction and strength of diversity effects differed between the latter and present study, in that strong negative effects (i.e., reduced decomposition rates in species mixtures) were reported by Swan and Palmer (2004). Thus, litter diversity effects on decomposition currently remain difficult to predict, suggesting that a better grasp of underlying mechanisms is needed to understand the context dependency of the relationship (Hättenschwiler and Gasser 2005, Zimmer et al. 2005, Swan and Palmer 2006a, b).

There are a variety of mechanisms that could cause effects of litter diversity on decomposition (Gartner and Cardon 2004, Hättenschwiler et al. 2005). Transfers between litter species differing in quality of nutrients and other essential compounds, or of inhibitory soluble compounds, may be effective, even in spite of possible dilution in aquatic environments (McArthur et al. 1994). Litter diversity effects on decomposition may also be caused by detritivore behavior, such as aggregation in litter bags (Presa Abós et al. 2006) coupled with preferential feeding on high quality litter in mixtures (Swan and Palmer 2006b). In the present study, litter bags were well colonized by invertebrates capable of feeding on leaves (A. Lecerf and G. Risnoveanu, unpublished data), suggesting that detritivores could have caused diversity effects in the streams studied here. Irrespective of the specific mechanisms involved, balance of positive and negative litter diversity effects may explain variability in the difference between observed and expected litter mass remaining across locations, litter species combinations, and even individual mixed species litter bags, the last, for example, through invertebrate aggregation effects (Presa Abós et al. 2006). 
TABLE 4. Summary of ANCOVA of the deviation between observed and expected litter mass remaining in mixed species litter bags placed in two streams of the Massif Central and the Carpathians (location).

\begin{tabular}{lrrrrrc}
\hline \hline \multicolumn{1}{c}{ Source of variation } & \multicolumn{1}{c}{ df } & \multicolumn{1}{c}{ SS } & SS (\%) & MS & \multicolumn{1}{c}{$F$} & $P$ \\
\hline Location & 1 & 0.455 & 4.0 & 0.455 & 5.5 & 0.058 \\
Riffle(location) & 6 & 0.497 & 4.4 & 0.083 & 1.9 & 0.087 \\
Species richness & 4 & 0.319 & 2.8 & 0.080 & 1.9 & 0.18 \\
Species composition(richness) & 20 & 0.822 & 7.3 & 0.041 & 0.9 & 0.54 \\
Location × richness & 4 & 0.132 & 1.2 & 0.033 & 0.4 & 0.78 \\
Location × composition(richness) & 20 & 1.523 & 13.5 & 0.076 & 1.7 & 0.034 \\
Expected litter mass remaining & 1 & 1.207 & 10.7 & 1.207 & 27.5 & $<0.001$ \\
Error & 143 & 6.275 & 56.1 & 0.044 & & \\
Total & 199 & 11.229 & 100.0 & & & \\
\end{tabular}

In contrast to decomposition rate, variability of litter mass remaining among mixtures differing in species composition was sensitive to altered litter species richness (Fig. 1b). This effect has also been noticed in other decomposition experiments, where the diversity of leaf litter (Schädler and Brandl 2005) or fungal decomposers (Dang et al. 2005) was manipulated and appeared to be due to a mathematical rather than biological mechanism.

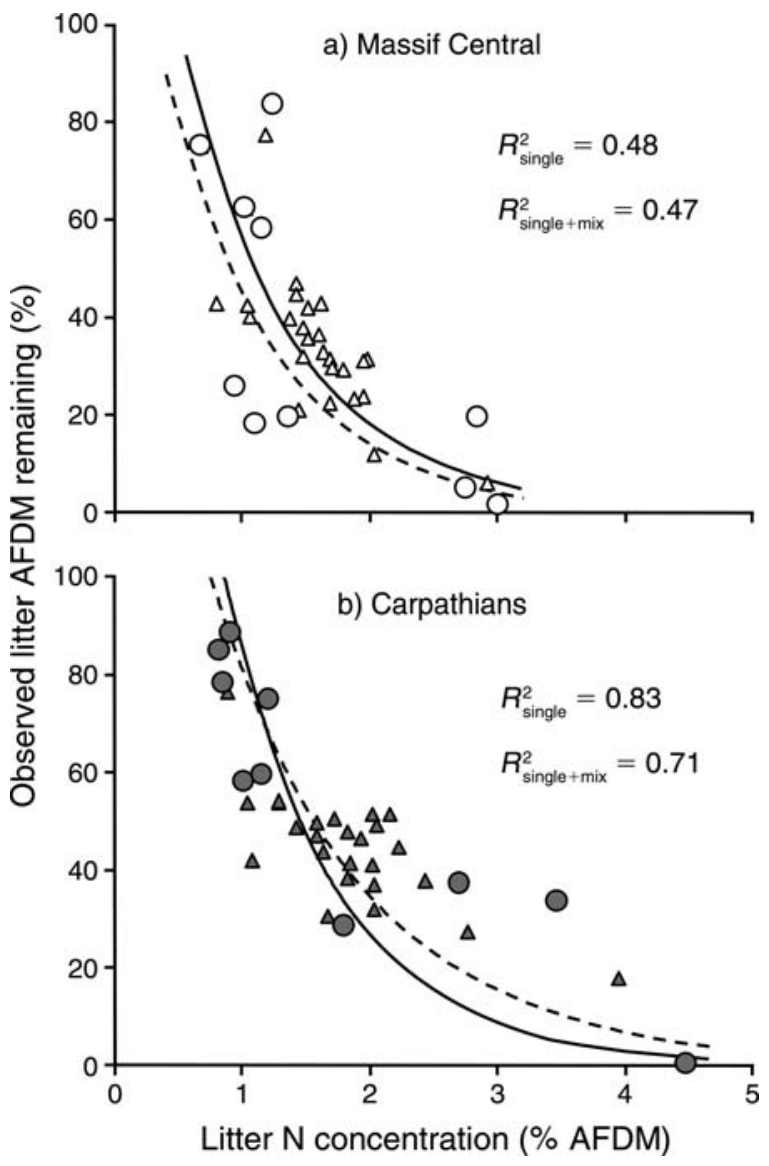

FIG. 3. Litter mass remaining as a function of initial litter $\mathrm{N}$ concentration of single species (circles) and mixed species (triangles) litter combinations in an (a) Massif Central, and (b) Carpathian stream. Symbols represent means per litter species combination. Exponential regression curves are shown for single species litter combinations (dashed lines) and single species plus mixed species litter combinations (solid lines).
This conclusion is in accordance with both theoretical considerations (Doak et al. 1998, Tilman et al. 1998) and results from biodiversity experiments addressing other aspects of variability (McGrady Steed et al. 1997, Tilman et al. 2006). Concordance of these results across such diverse studies suggests that reduction of variability in process rates is a common phenomenon associated with high diversity, although strength of the effect can be modulated by the structure of communities (Cottingham et al. 2001, Dang et al. 2005).

Species composition of litter mixtures was the main determinant of decomposition rate, accounting for nearly two thirds of the total variation in litter mass remaining in this study (Table 3 ). This strong effect reflects large differences in decomposability among litter species and the underlying well known control of decomposition rate by litter quality (Melillo et al. 1982, Gessner and Chauvet 1994). That the initial N concentration of litter can be a useful predictor of litter mass remaining is in accordance with a range of other studies (Webster and Benfield 1986, Heal et al. 1997, Hobbie 2005) and apparently holds in the same way for litter mixtures (Fig. 3a, b). However, some caution is needed in the interpretation of this result, because relationships were partly determined by clusters of some high $\mathrm{N}$ and low $\mathrm{N}$ species in both streams (Fig. 3a, b). Moreover, correlations between initial litter $\mathrm{N}$ concen tration and decomposition rate may not accurately indicate $\mathrm{N}$ limitation of decomposition. One reason is that $\mathrm{N}$ concentration can covary with other litter quality traits (e.g., lignin or tannin concentrations), which in turn control decomposition rate (Hobbie 2005).

Litter mass remaining when litter bags were retrieved from streams was comparable between locations in the present study (Fig. 1a). However, litter was exposed in the field nearly three times longer in the Carpathian stream, where decomposition rates thus were much lower. Since stream characteristics, other than temper ature, were similar between locations, particularly concentrations of dissolved nutrients (Table 1), differ ences in thermal regimes were likely an important environmental factor contributing to variation in decomposition rates between locations (cf. Richardson 1992). Variation among streams in population densities of detritivores can confound response patterns of 
decomposition to temperature (Irons et al. 1994, Robinson et al. 1998, Dobson et al. 2002). However, although nearly $2000 \mathrm{~km}$ apart, detritivore communities did not notably differ between the two streams (A. Lecerf and G. Risnoveanu, unpublished data), suggesting that direct temperature effects on metabolic activity of decomposers were most influential.

In conclusion, our results indicate that litter diversity clearly reduces variability of decomposition rates. Effects on decomposition rate per se appear to depend on context, and, when present, they were small compared to those of litter quality or environmental factors (e.g., temperature). It is possible, however, that diversity of riparian trees affects litter decomposition more than was captured in our short term experiment. For example, riparian tree richness may increase the number of fungal species degrading leaves in streams (Laitung and Chauvet 2005), which in turn can enhance litter consumption by invertebrates (Lecerf et al. 2005). Similarly, a diet of mixed species litter may increase invertebrate growth rate (Swan and Palmer 2006a). Detritivore secondary production therefore may be enhanced in streams lined by diverse riparian vegetation and in turn lead to a positive feedback on litter decomposition in the long run (i.e., at time scales of months and years), as has been observed in a whole stream litter exclusion experiment (Wallace et al. 1999).

\section{ACKNOWLEDGMENTS}

We are indebted to Carmen Postolache and Didier Lam brigot for nutrient analyses of stream water and leaf litter, and to John Richardson, Christian Dang, and two anonymous reviewers for constructive comments on previous drafts of the manuscript. This study was carried out with financial support from the EU Commission within the RIVFUNCTION project (contract EVK1 CT 2001 00088).

\section{Literature Cited}

Berg, B., and C. McClaugherty. 2003. Plant litter: decomposi tion, humus formation, carbon sequestration. Springer Verlag, Berlin, Germany.

Cardinale, B. J., K. Nelson, and M. A. Palmer. 2000. Linking species diversity to the functioning of ecosystems: on the importance of environmental context. Oikos 91:175 183.

Cottingham, K. L., B. L. Brown, and J. T. Lennon. 2001. Biodiversity may regulate the temporal variability of ecological systems. Ecology Letters 4:72 85.

Coûteaux, M. M., P. Bottner, and B. Berg. 1995. Litter decomposition, climate and litter quality. Trends in Ecology and Evolution 10:63 66.

Covich, A. P., M. C. Austen, F. Barlocher, E. Chauvet, B. J. Cardinale, C. L. Biles, P. Inchausti, O. Dangles, M. Solan, M. O. Gessner, B. Statzner, and B. Moss. 2004. The role of biodiversity in the functioning of freshwater and marine benthic ecosystems. BioScience 54:767 775 .

Dang, C. K., E. Chauvet, and M. O. Gessner. 2005. Magnitude and variability of process rates in fungal diversity litter decomposition relationships. Ecology Letters 8:1129 1137.

Doak, D. F., D. Bigger, E. K. Harding, M. A. Marvier, R. E. O'Malley, and D. Thomson. 1998. The statistical inevitability of stability diversity relationships in community ecology. American Naturalist 151:264 276.

Dobson, M., A. Magana, J. M. Mathooko, and F. K. Ndegwa. 2002. Detritivores in Kenyan highland streams: more evidence for the paucity of shredders in the tropics? Freshwater Biology 47:909 919.

Finn, J. A. 2001. Ephemeral resource patches as model systems for diversity function experiments. Oikos 92:363 366.

Gartner, T. B., and Z. G. Cardon. 2004. Decomposition dynamics in mixed species leaf litter. Oikos 104:230 246.

Gessner, M. O., and E. Chauvet. 1994. Importance of stream microfungi in controlling breakdown rates of leaf litter. Ecology 75:1807 1817.

Gessner, M. O., K. Suberkropp, and E. Chauvet. 1997. Decomposition of plant litter by fungi in marine and freshwater ecosystems. Pages 303332 in D. T. Wicklow and B. Soderstrom, editors. The Mycota, Vol. IV: Environ mental and microbial relationships. Springer Verlag, Berlin, Germany.

Hattenschwiler, S., and P. Gasser. 2005. Soil animals alter plant litter diversity effects on decomposition. Proceedings of the National Academy of Sciences (USA) 102:1519 1524.

Hattenschwiler, S., A. V. Tiunov, and S. Scheu. 2005. Biodiversity and litter decomposition in terrestrial ecosys tems. Annual Review of Ecology, Evolution and Systematics 36:191 218.

Heal, O. W., J. M. Anderson, and M. J. Swift. 1997. Plant litter quality and decomposition: an historical overview. Pages 3 32 in G. Cadish and K. E. Giller, editors. Driven by nature: plant litter quality and decomposition. CAB International, London, UK.

Hector, A., A. J. Beale, A. Minns, S. J. Otway, and J. H. Lawton. 2000. Consequences of the reduction of plant diversity for litter decomposition: effects through litter quality and microenvironment. Oikos 90:357 371.

Hector, A., et al. 1999. Plant diversity and productivity experiments in European grasslands. Science 286:1123 1127.

Hobbie, S. E. 2005. Contrasting effects of substrate and fertilizer nitrogen on the early stages of litter decomposition. Ecosystems 8:644 656.

Hooper, D. U., et al. 2005. Effects of biodiversity on ecosystem functioning: a consensus of current knowledge. Ecological Monographs 75:3 35 .

Irons, J. G., M. W. Oswood, R. J. Stout, and C. M. Pringle. 1994. Latitudinal patterns in leaf litter breakdown: Is temperature really important? Freshwater Biology 32:401 411.

Jonsson, M., and B. Malmqvist. 2000. Ecosystem process rate increases with animal species richness: evidence from leaf eating, aquatic insects. Oikos 89:519 523.

Kuehn, K. A., D. Steiner, and M. O. Gessner. 2004. Diel mineralization patterns of standing dead plant litter: impli cations for $\mathrm{CO}_{2}$ flux from wetlands. Ecology 85:2504 2518 .

Laitung, B., and E. Chauvet. 2005. Vegetation diversity increases species richness of leaf decaying fungal communi ties in woodland streams. Archiv fur Hydrobiologie 164:217 235.

Lecerf, A., M. Dobson, C. K. Dang, and E. Chauvet. 2005. Riparian plant species loss alters trophic dynamics in detritus based stream ecosystems. Oecologia 146:432 442.

LeRoy, C. J., and J. C. Marks. 2006. Litter quality, stream characteristics and litter diversity influence decomposition rates and macroinvertebrates. Freshwater Biology 51:605 617.

Loreau, M. 1998. Separating sampling and other effects in biodiversity experiments. Oikos 82:600 602 .

McArthur, J. V., J. M. Aho, R. B. Rader, and G. L. Mills. 1994. Interspecific leaf interactions during decomposition in aquatic and floodplain ecosystems. Journal of the North American Benthological Society 13:57 67.

McGrady Steed, J., P. M. Harris, and P. J. Morin. 1997. Biodiversity regulates ecosystem predictability. Nature 390: 162165.

Melillo, J. M., J. D. Aber, and J. F. Muratore. 1982. Nitrogen and lignin control of hardwood leaf litter decomposition dynamics. Ecology 63:621 626 . 
Moore, J. C., et al. 2004. Detritus, trophic dynamics and biodiversity. Ecology Letters 7:584 600 .

Moore, T. N., and P. G. Fairweather. 2006. Decay of multiple species of seagrass detritus is dominated by species identity, with an important influence of mixing litters. Oikos 114:329 337.

Petersen, R. C., and K. W. Cummins. 1974. Leaf processing in a woodland stream. Freshwater Biology 4:343 368.

Presa Abós, C., F. Lepori, B. G. McKie, and B. Malmqvist. 2006. Aggregation among resource patches can promote coexistence in stream living shredders. Freshwater Biology 51:545 553 .

Richardson, J. R. 1992. Coarse particulate detritus dynamics in small, montane streams of southwestern British Columbia. Canadian Journal of Fisheries and Aquatic Sciences 49:337 346.

Robinson, C. T., M. O. Gessner, and J. V. Ward. 1998. Leaf breakdown and associated macroinvertebrates in alpine glacial streams. Freshwater Biology 40:215 228.

Schadler, M., and R. Brandl. 2005. Do invertebrate decom posers affect the disappearance rate of litter mixtures? Soil Biology and Biochemistry 37:329 337.

Schmid, B., A. Hector, M. A. Huston, P. Inchausti, I. Nijs, P. W. Leadley, and D. Tilman. 2002. The design and analysis of biodiversity experiments. Pages 6175 in M. Loreau, S. Naeem, and P. Inchausti, editors. Biodiversity and ecosystem functioning: synthesis and perspectives. Oxford University Press, Oxford, UK.

Spehn, E. M., et al. 2005. Ecosystem effects of biodiversity manipulations in European grasslands. Ecological Mono graphs 75:37 63 .

StatSoft. 2001. Statistica 6.0: Electronic statistics textbook. 〈http://www.statsoft.com/textbook/stathome.html

Swan, C. M., and M. A. Palmer. 2004. Leaf diversity alters litter breakdown in a Piedmont stream. Journal of the North American Benthological Society 23:15 28 .
Swan, C. M., and M. A. Palmer. 2006a. Composition of speciose leaf litter alters stream detritivore growth, feeding activity and leaf breakdown. Oecologia 147:469 478.

Swan, C. M., and M. A. Palmer. 2006b. Preferential feeding by an aquatic consumer mediate non additive decomposition of speciose leaf litter. Oecologia 149:107 114.

Tilman, D., C. L. Lehman, and C. E. Bristow. 1998. Diversity stability relationships: statistical inevitability or ecological consequence? American Naturalist 151:277 282.

Tilman, D., P. B. Reich, and J. Knops. 2006. Biodiversity and ecosystem stability in a decade long grassland experiment. Nature 441:629 632.

Tilman, D., P. B. Reich, J. Knops, D. Wedin, T. Mielke, and C. Lehman. 2001. Diversity and productivity in a long term grassland experiment. Science 294:843 845 .

van Ruijven, J., and F. Berendse. 2005. Diversity productivity relationships: initial effects, long term patterns, and under lying mechanisms. Proceedings of the National Academy of Sciences (USA) 102:695 700 .

Wagener, S. M., M. W. Oswood, and J. P. Schimel. 1998 Rivers and soils: parallels in carbon and nutrient processing. BioScience 48:104 108.

Wallace, J. B., S. L. Eggert, J. L. Meyer, and J. R. Webster. 1999. Effects of resource limitation on a detrital based ecosystem. Ecological Monographs 69:409 442.

Wardle, D. A., K. I. Bonner, and K. S. Nicholson. 1997. Biodiversity and plant litter: experimental evidence which does not support the view that enhanced species richness improves ecosystem function. Oikos 79:247 258.

Webster, J. R., and E. F. Benfield. 1986. Vascular plant breakdown in freshwater ecosystems. Annual Review of Ecology and Systematics 17:567 594.

Wojdak, J. M. 2005. Relative strength of top down, bottom up, and consumer species richness effects on pond ecosystems. Ecological Monographs 74:489 504.

Zimmer, M., G. Kautz, and W. Topp. 2005. Do woodlice and earthworms interact synergistically in leaf litter decomposi tion? Functional Ecology 19:7 16. 